\title{
Acute disseminated encephalomyelitis after treatment with Japanese B encephalitis vaccine (Nakayama-Yoken and Beijing strains)
}

\author{
Etsuo Ohtaki, Toyojiro Matsuishi, Yukiko Hirano, Kihei Maekawa
}

\footnotetext{
Department of

Pediatrics and Child Health, Kurume University School of Medicine, Kurume, Japan

Japan

T Ohtaki

Department of

Pediatrics, Tokyo

Women's Medical

College, Tokyo, Japan

Y Hirano

Department of

Pediatrics, Jikei

University School of

Medicine, Tokyo,

Japan

K Maekawa

Correspondence to:

Dr Etsuo Ohtaki,

Department of Pediatrics

and Child Health, Kurume University School of

Medicine, 67 Asahi-machi,

Kurume City 830, Japan.

Received 21 March 1995

Accepted 21 April 1995
}

\begin{abstract}
Seven children with acute disseminated encephalomyelitis (ADEM) after treatment with Japanese $B$ encephalitis vaccine (JBEV) (Nakayama-Yoken strain 1968-88 and Beijing strain 1989-93) were identified by mailed questionnaires and by compilation of previously published case reports. It was considered that encephalomyelitis might have been related to vaccine treatment as the vaccine is derived from mouse brain tissue infected with Japanese B encephalitis virus, a potentially cross reactive antigen. The incidence of severe neurological complications associated with the newer Japanese B encephalitis Beijing strain vaccine seemed to be less than one case per 1000000 , which is similar to the incidence of neurological complications associated with the older NakayamaYoken strain vaccine.
\end{abstract}

(F Neurol Neurosurg Psychiatry 1995;59:316-317)

Keywords: acute disseminated encephalomyelitis; Japanese B encephalitis vaccine

Encephalitis due to Japanese B virus is one of the most common causes of epidemic viral encephalitis in the world. It occurs in annual epidemics in Asia, affecting residents and travellers to the region. The disease is often fatal or crippling. ${ }^{1}$ Beginning in 1989, Japanese B encephalitis vaccine (JBEV) was derived from Beijing strain antigens ${ }^{2}$ rather than the Nakayama-Yoken strain that had been used since $1954 .^{3}$ Because of occasional cases of Japanese encephalitis among travellers, the US Public Health Service obtained an investigational new drug exemption (IND 1824). ${ }^{4}$ Although there have been no studies of the neurological complications of JBEV in Japan since that by Okinaka et al ${ }^{5}$ in 1967, case reports of acute disseminated encephalomyelitis (ADEM) after JBEV have been reported by Matsukura et $a l^{6}{ }^{6}$ Kanesaki et $a l,{ }^{7}$ and Ohtaki et al. ${ }^{8}$ We identified cases by mailed questionnaires and collected the previous reports of neurological complications due to JBEV Beijing and Nakayama-Yoken strains in an effort to update the study by Okinaka et al. ${ }^{5}$

\section{Patients and methods}

The questionnaire was intended to screen for potential patients with neurological complications after treatment with JBEV. Forms were mailed to 162 medical institutions including paediatric departments in medical colleges, schools of medicine, children's hospitals, and rehabilitation facilities for children, all facilities that might be served by paediatic neurologists. Acute disseminated encephalomyelitis was defined, for the purposes of the questionnaire, as an acute inflammatory disease with perivenous lymphocytic infiltration and scattered demyelinating foci in the white matter of the CNS. The presence of characteristic CNS lesions was confirmed by CT or MRI. The symptoms of ADEM must have appeared abruptly within one month after vaccination. Other similar neurological conditions must have been ruled out. We also identified cases of neurological complications associated with JBEV from the Japanese and English medical literature.

\section{Results}

Results from the 120 returned questionnaires (reply rate $74 \%$ ), combined with a review of previous reports identified seven children with ADEM after treatment with JBEV (table). Other neurological complications associated with the Japanese $B$ vaccine included two patients with encephalitis (one having received the Nakayama-Yoken and the other the Beijing strain vaccine), one patient with encephalopathy after the Beijing vaccine, one patient with transient hemiplegia after the Beijing vaccine, and three patients with aseptic meningitis after the Nakayama-Yoken vaccine.

\section{Discussion}

Japanese B encephalitis is an important public health concern not only in Japan but also in other parts of east Asia. ${ }^{1}$ Japanese B 
Seven patients with acute disseminated encephalomyelitis after treatment with fapanese B encephalitis vaccine

\begin{tabular}{|c|c|c|c|c|c|c|}
\hline Patient & Age/sex & $\begin{array}{l}\text { Type of } \\
\text { strain }\end{array}$ & $\begin{array}{l}\text { Date of } \\
\text { inoculation }\end{array}$ & Date of onset & Symptoms at onset & $\begin{array}{l}\text { Neurological } \\
\text { sequelae }\end{array}$ \\
\hline 1 & $1 / \mathrm{F}$ & $\mathrm{N}-\mathrm{Y}$ & 6 July 1968 & 11 July & Fever, convulsion, somnolence & $\begin{array}{l}\text { MR, epilepsy. } \\
\text { Hemiplegia. }\end{array}$ \\
\hline 2 & $6 / \mathrm{M}$ & $\mathrm{N}-\mathrm{Y}$ & 21 June 1978 & 30 June & Fever, somnolence, gait disturbance & None \\
\hline 3 & $7 / \mathrm{F}$ & $\mathrm{N}-\mathrm{Y}$ & Unknown 1979 & $\begin{array}{l}2 \text { days after } \\
\text { vaccination }\end{array}$ & Fever, diplopia, gait disturbance. Urinary incontinence & None \\
\hline 5 & $3 / \mathrm{F}$ & B & 13, 20 June 1989 & 21 June & $\begin{array}{l}\text { Fever, convulsion, gait disturbance, urinary incontinence } \\
(\text { MBP } 8.5 \mathrm{ng} / \mathrm{ml})\end{array}$ & None \\
\hline 6 & $6 / \mathrm{F}$ & B & $\begin{array}{l}25 \text { June, } 7 \text { July } \\
1989\end{array}$ & 21 July & $\begin{array}{l}\text { Impaired vision, fever, somnolence, meningeal sign, } \\
\text { gait disturbance, urinary incontinence }\end{array}$ & None \\
\hline 7 & $5 / M$ & B & 30 May 1990 & 16 June & $\begin{array}{l}\text { Fever, meningeal signs, urinary incontinence, gait disturbance } \\
(\text { MBP } 18.5 \mathrm{ng} / \mathrm{ml})\end{array}$ & None \\
\hline
\end{tabular}

$\mathrm{M}=$ male; $\mathrm{F}=$ female; $\mathrm{N}-\mathrm{Y}=$ Nakayama-Yoken strain; $\mathrm{B}=$ Beijing strain; $\mathrm{MBP}=$ myelin basic protein in $\mathrm{CSF}(\mathrm{normal}<4 \cdot 0 \mathrm{ng} / \mathrm{ml}) ; \mathrm{MR}=\mathrm{mental}$ retardation.

encephalitis vaccine derived from the Nakayama-Yoken strain of the virus was developed in $1954 .^{24} \mathrm{~A}$ highly purified vaccine derived from the Beijing-1 strain was developed in 1989. ${ }^{2}$ The annual incidence of Japanese B encephalitis was decreased greatly to less than 60 cases per year between 1980 and $1993 .{ }^{9}$ The efficacy of vaccination was shown in the northern Thai Province in 1988. ${ }^{1}$ Because the JBEV contains material from infected mouse brain, postvaccination ADEM might occur as the result of an immune mediated process. Acute disseminated encephalomyelitis has been reported to occasionally occur about one month after vaccination. ${ }^{10}$ The differential diagnosis of acute encephalopathy includes viral encephalitis, multiple sclerosis, progressive multifocal leukoencephalopathy, cerebrovascular disorders, leukodystrophy, and other neurological disorders. The observed clinical course, appropriate viral titres, findings in CSF, electroencephalography, and MRI findings are useful for differentiating these diseases. A raised myelin basic protein concentration in the CSF is especially suggestive of ADEM. We hypothesised that inoculation with JBEV might lead directly to the development of this disorder. Other potential neurological complications, such as aseptic meningitis, encephalitis, encephalopathy, and transient hemiplegia have shown no correlation with the current version of the vaccine.

About $60 \%$ of school aged children in Japan receive JBEV every year. ${ }^{11}$

The incidence of neurological complications associated with the Beijing strain derived vaccine is likely less than 1 per $1000000,{ }^{12}$ even if one assumes that other neurological complications associated with the vaccine equal those associated with the older Nakayama-Yoken derived vaccine. We conclude that the JBEV is safe but that neurological complications, especially ADEM, may occasionally occur within one month of treatment.

This research was supported in part by a grant entitled "adverse effect of immunization", awarded by the Ministry of Health and Welfare, Japan. We thank Drs Matsusaka Tetsuo (Department of Pediatrics, Nagasaki University School of Medicine), Hirohumi Kaku (Department of Pediatrics, $S$ Marianna University School of Medicine), Pediatrics, S Marianna University School of Medicine), and Kimiko Neurological Hospital)

1 Hoke $\mathrm{CH}$, Nisalak A, Sangawhipa N, et al. Protection against Japanese encephalitis by inactivated vaccines. N Engl f Med 1988;319:608-14.

2 Kitano T. Japanese B encephalitis vaccine. In: Kimura M, Takahashi M, eds. Advance of vaccination. Osaka: Iyaku Takahashi M, eds. Advance of vaccination. Osaka: lyaku

3 Takaku K, Yamashita T, Osanai T, et al. Japanese encephalitis purified vaccine. Biken fournal 1968;11: 25-39.

4 Japanese encephalitis: report of a World Health Organization Working Group. MMWR CDC Surveill Summ 1984;33:119-25.

5 Okinaka S, Toyokura Y, Tsukakoshi $\mathrm{H}$, et al. Physical and neurological reactions following Japanese $B$ encephalitis vaccine, with special reference to neurological complications. Advances in Neurological Sciences 1967;11:410-24. (In Japanese.)

6 Matsukura $M$, Shimomura $M$, Nunoi $H$. A case of acute disseminated encephalomyelitis following vaccination against Japanese encephalitis [abstract]. Brain Dev 1980;2:323.

7 Kanesaki T, Watanabe K, Shiomi M, et al. A case of acute disseminated encephalomyelitis following Japanese encephalitis vaccine. Clinical Virology 1981;9:318. (In apanese.

8 Ohtaki E, Murakami Y, Komori H, Yamashita Y, Matsuishi T. Acute disseminated encephalomyelitis after Japanese B encephalitis vaccination. Pediatr Neurol 1992;8:137-9.

9 The annual report of the incidence of epidemic infectious disease. The trend of the fapanese public health. Tokyo: Health and Welfare Statistics Association. Kosaido Press Co, Tokyo 1994:440. (In Japanese.)

10 Dyken PR. Disseminated encephalomyelitis. In: Swaiman KF. Pediatric neurology: principles and practice. St Louis: CV Mosby, 1989:497-8.

11 Kitano $T$. The effect and the incidence of inoculation in Japanese B encephalitis vaccine. Fournal of Pediatric Japanese B encephalitis vaccine. Fournal
Practice 1993;11:2165-70. (In Japanese.)

12 Miettinen OS. Estimability and estimation in case-referent studies. Am $\mathcal{F}$ Epidemiol 1976;103:226-35. 